\title{
Web Supplement to: Identification of Protein Modifications Using MS/MS De Novo Sequencing and the OpenSea Alignment Algorithm
}

Brian C. Searle ${ }^{1 \dagger}$, Surendra Dasari ${ }^{1}$, Phillip A. Wilmarth ${ }^{2}$, Mark Turner ${ }^{1 \dagger}$, Ashok P. Reddy ${ }^{1}$, Larry L. David ${ }^{2}$, and Srinivasa R. Nagalla ${ }^{1^{*}}$

Department of Pediatrics ${ }^{1}$ and School of Dentistry ${ }^{2}$, Oregon Health \& Sciences University, 3181 SW Sam Jackson Park Road, Portland, OR 97239-3098

† Present Address: Proteome Software Inc., 1337 SW Bertha Blvd., Portland, OR 97219-2039

Journal of Proteome Research (Submitted)

\section{Supplemental Tables}

- List of modifications that are used by the auto-interpretation routine of OpenSea algorithm.

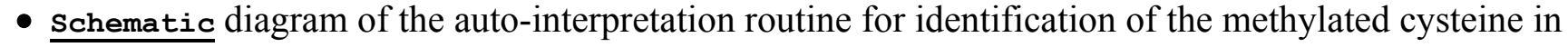
gamma-S lens crystallin.

- Comparision of performance of Peaks Batch Version 2.2 and LutefiskXP on the ion trap control mixture dataset.

- Comparision of performance of Peaks Batch Version 2.2 and LutefiskXP on the Q-TOF control mixture dataset.

\section{Control Mixture Raw Data}

E-mail dasaris@ohsu.edu for access to.DTA download.

- Q-TOF SEQUEST .DTA Files (.ZIP)

- ION-TRAP SEQUEST .DTA Files (.ZIP)

\section{Program Availability}

A copy of the program is available under material transfer agreement (for non-commercial academic use only).

Please direct your requests for program access to nagallas@ohsu.edu.

OpenSea@ 2004 OHSU. All rights reserved.

This site developed by Surendra Dasari and maintained by Matthew J. Rodland

Last updated on Tuesday, December 21, 2004 at 1:02:08 PM 